\title{
A sensibilidade brasileira de Manuel Bandeira
}

a) O descobrimento dum novo mundo.

"-Quem, antes de nós, tinha descoberto, mesmo, o Brasil?

-Ninguéem."

Foi nestas palavras que Álvaro Moreyra, em 1946, caracterizou a sua geração. Era essa geração que inclui o poeta Manuel Bandeira, seu "marco zero": "Manuel Bandeira, por tudo marca a idade da nossa geração", escreveu, continuando: "Uma geração justamente sem idade." 1 Devemos supôr que Álvato Moreyra falava de ciência certa, porque êle e Bandeira eram velhos amigos, chegando os dois à maturidade pouco antes da guerra de 1914, origem do seu ceticismo pelas ideias gerais e a sua sêde de vida inmediata. ${ }^{2}$

Viu Manuel Bandeira o Brasil de uma maneira tão inédita que o seu amigo podia falar com razão de um descobrimento? A geografia aproveitada para fonte de pitoresco ou exaltação nacional não a descobriu nenhum escritor moderno lá onde a literatura quase se iniciou com os versos às ilhas da Maré e de Itaparica. Insurgiramse, até, Bandeira e a sua geração, contra a "poesia multicôr", ${ }^{3}$ própria para as crianças recitarem, que pouco antes tinha sido propagada por Olavo Bilac. Nem foi preciso que Bandeira viajasse, como Gonçalves Dias, fora da pátria, para apreciá-la saudosamente. Nenhum exílio exaltou na sua alma o ambiente brasileiro. A vida the correu calma demais, ainda que se tivessem malogrado os seus sonhos de arquiteto. Não the ensinou novas maneiras de ver a viagem que o levou tísico a uma aldeia suiça em 1913: o Brasil estava já dentro do seu coração, naturalmente, sem ênfase alguma, como conjunto de lembranças queridas - o mar, ${ }^{4}$ a amada, a familia. 
Em 1908, vários anos antes da viagem, aparece na obra do poeta o primeiro reflexo do Nordeste natal. A costa do Ceará entrevê-se no soneto Verdes mares. Enxerga-a de longe, porém, da banda do mar, do cais, de fora. Irônicamente, como mofando-se de si mesmo e daquela sua gente que não sabia ver a terra real nem o espetáculo vulgar do desembarque sem recitar as linhas românticas do conhecimento de todos:

"Verdes mares bravios..."

Cita um sujeito que jamais leu Alencar.

A ironia anti-sentimental de então escondia um temperamento romântico reprimido. Delatam-no as impressões fugidias, acompanhadas pela exclamação comovida:

Passa. Tão frágil! Deus a leve, onde ela vá. 5

A fusão dos contrastes que a emoção irônica opera entre o deslumbramento pelo espetáculo da natureza - vasto mar, praia doirada e o reboliço dos homens, neste caso feito de risos, atrapalhações e gritaria, caraterizará desde então a poesia mais pessoal de Bandeira. A feição autobiográfica aproxima-o de outros poetas, subjetivos a ponto de se tornarem difíceis de interpretar, grandes conhecedores do seu próprio país, grandes amigos do seus amigos, amantes elegíacos da vida que não lhes brindou a felicidade sonhada, cantores das coisas mais simples da sua existência: "Quero a delícia de poder sentir as coisas mais simples." (Belo belo). Tal fôra Antônio Machado, tal $\mathrm{Tu}-\mathrm{Fu}$, velho poeta chinês do século oito:

Quando sinto surgir dentro de mim a amargura

Sento-me num prado, canto, soluço,

Enxugo as lágrimas com ambas as mãos.

$\mathrm{Na}$ estrada sem fim dos irrequietos homens

Que importa que seja longa on breve a vida? 6

Tu-Fu, como Bandeira, estava saturado de tradições e leituras, mas a poesia dêles parece jorrar espontâneamente, ao capricho das circunstâncias: "Fiz -afirmao Bandeira- algunnas tentativas de escrever poesias sem apoio nas mas circunstâncias. Tôdas malogradas. Sou poeta de circunstâncias e desabafos." "7 Assim acertou 
em exprimir o Brasil, mas um Brasil secreto, inoficial, sentido diretamente. $^{8}$ A primeira vista parece incrível que tenha podido fazer tanto, na ignorância do sertão, de quase tudo o que não seja cidade. As cidades conheceas, sim, as grandes $o$ as pequenas, por ter vivido em muitas - o Recife, São Paulo, o Rio, Santos, Teresópolis, Petrópolis... Através de las divinha o resto:

\author{
O largo \\ O ribeirão \\ A matriz \\ E a poesia dos casarões quadrados \\ (A luz elétrica é forasteira) ${ }^{9}$
}

Manuel Bandeira foi inventando um Brasil para uso pessoal, intuitivamente, feito da experiência de todos os dias. Nisto difere radicalmente de outros poetas mais voluntariosos como Ronald de Carvalho ou Raul Bopp. Não foi Carvalho más êle. Bandeira, quem seguiu o conselho pôsto em verso pot aquêle:

Olha a vida primieiro, longamente, enternecidamente,

Como quem a quer adivinhar...

Olha a vida, rindo ou chorando, frente a frente,

Deixa depois o coração falar. ${ }^{10}$

Noutra ocasião disseram-se os efeitos que em poemas ocasionais o poeta sabe tirar de lugares e gente bem brasileiros. Mas não é ali que se acha a imagem mais sugestiva do seu Brasil. Para isso são a maioria daquelas poesias demasiado ocasionais, o que se deixa ver por exemplo em Belém do Pará ou Ouro Preto ou Discurso em louvor da aeromoça. O que sensibiliza o leitor brasileiro - se merece confiança o testemunho dos escritores Rachel de Queiroz e Graciliano Ramos ou o do compositor Camargo Guarnieri- o que faz vibrar a alma dêle são as poesias de puro sentimento lírico onde o brasileirismo se resume na sensibilidade: tal o abandôno do orgulho na Balada de Santa Maria Egipciaca, a espirtiualização feminina em Um sorriso, a simpatia entre as raças em Irene no céu:

\title{
b) A sensibilidade brasileira.
}

Antes que as alusões a determinadas cidades ou tipos populares, o que aparece na poesia de Bandeira é a alma do Brasil, vista à luz da emoção. Ainda seguia o poeta trilhos parnasianos quando 
em 1906 escreve o poema Renúncia. Porém a nota melancólica, ali ferida, nuncai mais deixará de ressoar. Mas Bandeira não encerrou em si a sua tristeza. Reagiu de-pressa contra a frieza artificial dos parnasianos. Expansivo, deixa correr livremente os queixumes amargos contra a sina negra, destruidora das suas ambições:

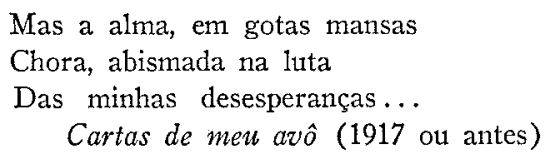

A reacção veio. Passa a insurgir-se contra a saudade lusitana; já não segue seu mestre António Nobre:

Que me importa o passado? A minha natureza

Repugna essa volúpia enorme da saudade.

O meu passado, ruinaria sem beleza!

Eu abomino a tua escura soledade.

Delírio

Assim escreve em 1914, ainda do sanatório de Clavadel, pouco antes do regresso ao Brasil, onde deixara a carreira abandonada e os amores desfeitos.

O caráter específicamente brasileiro da sensibilidade de Manuel Bandeira não se encontra, porém, na melancolia ruça das primeiras poesias, nem equivale simplesmente à índole romântica, reafirmada ainda entem, nas belas Sextilhas românticas de 1945 :

Sou romântico? Concedo.

Exibo, sem evasiva,

A alma ruim que Deus me deu.

Suponho que a emotividade brasileira corresponde antes a uma brandura que mal encobre os ímpetos violentos, "o fundo intacto de ternura, / Agora embravecida e mansa agora..." (Confissão, 1917 ou antes). O poeta tem as suas "cóleras homicidas" (Mar bravo, 1913). Com maior freqüência, êle se faz terno, para exprimir "o gôsto humilde da tristeza" (Quando perderes o gôsto humilde da tristeza, 1919 ou antes). E se apieda dos fracos como uma ternura ardente de franciscano: 
E tudo tem aquêle carácter impressivo que faz meditar:

Entêrro a pé ou a carrocinha de leite puxada por um bodezinho manhoso.

A estrada (1921)

Outras vezes prorrompe intensamente doce, a paixão amorosa "Meu verso é sangue. Volúpia ardente..." (Desencanto, 1912). O amor se lhe afigura então "volúpia da água e da chama" (Poemeto erótico, 1917 o uantes). A natureza tôda passa a incitar os sentidos: as névoas, queridas do poeta melancólico, se vão movendo "em voluptuoso espreguiçar de forma nua" (Paisagem noturna, 1912); o mar se estremece no luar "como uma carne de mulher sob a carícia" ( $N$ a solidão das noites úmidas, 1919 ou antes) ; as terras desconhecidas se povoam de "púbis a não poder mais" (Canção das duas Indias, 1931). Mas essa voluptuosidade do poeta não se torna nunca doentia ou vil: sempre se dá franca — "sem evasiva" - e nua, tal qual as suas sereias, que the aparecem "de braços nus e nádegas redondas" (A sereia de Lenau, 1919 ou antes). Não lhe metem medo os antigos tabus. Como tanto ibérico, ainda que sem abusar, êle tem os seus momentos de realismo crudo, brutal, quando até "o cambrone" se faz "núcleo de poesia (la fraîcheur des latrines!)" (Infância, 1948).

Nem falta a rebeldia diabólica, que impele a dúvidas sacrílegas o católico que há nele, sempre apegado ao crucifixo de marfim da família :

- Meu Jesus-Cristinho!

Mas Jesus-Cristinho nem se incomodou.

Conto cruel (1936 ou antes)

O catolicismo de Bandeira! Deixa-nos longe do misticismo todo exterior dos simbolistas, ainda quando a poesia de Bandeira adota a forma da oração. O profano e o sagrado mezclam-se também em varias das suas poesias amorosas, e as santas que lá aparecem tantas vezes são duma santidade suspeita: "Nem Santa nunca foi para mim a mulher sem pecado" (Os nomes, 1953). Como no amor profano, o poeta é um realista desconfiado em matéria de religião. Ficam alheias à sua natureza a teologia e a metafísica. Nem o aparato da igreja o seduz. Há nos poemas dêle santos e santas, mas há também o desejo de ter "a coragem de ser um novo santo / sem fé num mundo além do mundo" (Soneto inglês N. 2, 1940 ou antes). Há céu e inferno, 
mas há também a dúvida de "morrer sem deixar porventura uma alma errante..." (A morte absoluta, 1940 ou antes). Ha orações devotas, mas há também a paródia dum ave-maria dirigido a uma "Virgem mal-sexuada. / Atribuladora dos aflitos" (Estrêla da man$h \tilde{a}$, entre 1920 e 1933). Ouve-se a Virgem Maria, vê-se sorrir o anjo da guarda do próprio poeta ( $O$ anjo da guarda, 1930 ou antes), e descreve-se a chegada do belo anjo da boa morte ( $O$ homem e a morte, 1945), ainda que Bandeira alhures confessa: "Os anjos!... Bem sei que não os há em parte alguma." (Jacqueline, 1936 ou antes). Esse catolicismo não é pois uma fé cega e doutrinária, senão uma parte integral da vida acostumada, tão integral como aquêle "crucifixo de marfim", ou como "a voz dos sinos" que ressoa através das suas poesias desde os dias na Suiça (Ao crepúsculo; Natal, 1913) até os anos quando ouve tocar o ângelus no bairro da Lapa (Última canção do beco, 1942). A sua voz passa para o momento da mais dorida angustia quando no poema $O s$ sinos (1924 ou antes) o sino do Bonfim - a boa morte que êle anseia- e o doce sino de Belém - "que graça êle tem!'- contedem com o da Paixão, a dura agonia que o poeta presenciou ao the morrerem os pais e a irmã.

O Brasil de hoje, que aspira a uma grandeza ainda impossivel, pode ver-se refletido na frustração do voluptuoso poeta, construtor malogrado, que sempre acaba por afirmar a vida:

E neste curto instante em que todo me exalto

De tudo o que não sou, gozo tudo o que invejo.

Plenitude (1914)

Por isso tinha razão Mário de Andrade, quando julgou que a tristeza de Bandeira era passageira apenas, tal qual a apregoada "tristeza brasileira", exagêro de patriotas desalentados. ${ }^{11}$

Os cariocas afugentam durante os dias do carnaval as misérias da vida cotidiana. Assim faz o poeta, mergulhando no "lirismo dos clowns de Shakespeare" (Poética, 1924 ou antes)), fantasiado de Pierrot:

Lá se me parte a alma levada No torvelim da mascarada Bacanal (1918) 
Tentativa vã: sempre acaba por aperceber-se de que

Tenho tudo que não quero

Não tenho nada que quero

Belo belo (1947)

O símbolo do palhaço, adotado por tanto poeta e artista miserável desde Baudelaire, ${ }^{12}$ êsse símbolo nada consolador se dissipará um dia com a melancolia do amante desiludido. Uma suave ironia salva Bandeira. Não se tóma demasiado a sério; sabe ver-se como se fôsse outrém. Como brasileiro legítimo, desconfiado de si, aberto a tôdas as influências, ${ }^{13}$ conhece melhor do que os orgulhosos hispanoamericanos ou angloamericanos a justa proporção da sua obra. Cedo sorriu da sentimentalidade dos seus "pobres versos comovidos!" (Versos escritos nágua, 1918). Se os faz, a culpa não é dêle:

\section{Foi-se me um dia a saúde Fiz-me arquiteto? Não pude! \\ Sou poeta menor, perdoai! \\ Testamento (1943) 14}

A expressão "poeta menor" deve entender-se no sentido de poeta de poesias breves, brevíssimas, de curto fôlego lírico. Talvez teria sido capaz de obras de pêso, como Moreyra afirmou ao falar da geração dêles, "mas só as pequeninas realizações os interessam." 15 Subsiste na expressão um equívoco saído do mesmo humor que o poeta tem pôsto em tantas "brincadeiras" suas, exemplificadas no poema Os voluntários do Norte, pastiche duma poesia patriótica do seriíssimo Tobias Barreto. As "piadas", plenamente compreensiveis para uns poucos amigos modernistas apenas, brotam-lhe da veia repentista de menino brincalhão.

Cedo abandonou o tom lúgubre dos modelos portugueses, mas nunca se libertou do doentio prazer dos solitários, a auto observação, elevada ao último grau de perfeição por un português, contemporâneo seu, Fernando Pessoa. Embora Bandeira não achasse que tinha uma alta missão a cumprir, nunca teve pretensões de vate ou de mestre. Basta-1he mantêr os dois pés no humilde chão que é de todos. Pronto desiludido, deixa-se levar de cidade em cidade, de casa em casa, fiel ao preceito simbolista: 
Como uma folha caida

Deixa-te assim também derivar pela vida, $E$ deixa transfundir-te, alma, na alma das cousas. Voz de fora (1906)

Maleável, participa o poeta na experimentação de várias gerações de escritores. Assim aperfeiçoa o instrumento sensível que lhe permite exprimir a sensibilidade complexa da sua gente: a sensualidade dela, a ironia, a ternura, o ardor, a espontaneidade, a sociabilidade exterior e também a fundamental solidão melancólica ainda que fàcilmente distraída - todos os matizes que definem a alma do brasileiro culto de hoje. Coincide com o sentir comum quando em resumo deseja do último poema,

Que fôsse terno dizendo as coisas mais simples e menos intencionais.

(1930 ou antes)

c) O ritmo e o som da lingua.

Das emoçóes vai-se em linha reta aos ritmos e aos sons que as modulam. Os simbolistas ensinaram a Bandeira a procurar a difícil misica interior. Assim introduziu novas formas mais soltas no Brasil, sobretudo o verso livre, o que o faz precursor dos modernistas brasileiros. Nesse sentido já estava experimentando antes da guerra de 1914, sob a influência de dois poetas franceses, Cros e Apollinaire, lidos no Mercure de France. ${ }^{16}$ Destas tentativas resultaram poemas como o Carinho triste de 1912. Logo depois da guerra, atacou o parnasianismo moribundo. Mais tarde, depois do triunfo do modernismo brasileiro, manifesta ruidosamente sua "libertinagem":

\section{Etou farto de lirismo comedido \\ Abaixo os puristas \\ Quero antes o lirismo dos loucos}

Poética (antes de 1924)

Parece indisciplina. Mas Bandeira não tem um temperamento anárquico. Pede liberdade para poder adotar o ritmo adequado. Inova seguindo o exemplo dado por outros poetas. Segue-os ao suprimir 
a pontuação, inclusive os pontos suspensivos da sua época de simbolismo inefável. Assim dá a poesia a mesma fluidez que possui a língua falada. Reproduz a lábia dos vendedores de brinquedos: "A perereca verde que de repente dá um pulo que engraçado" (Camelots, 1930 ou antes). Obtêm o efeito da réplica inesperada, no famoso poema Pneumotórax. Omitindo pausas sintetiza a desgraça: "Sim, já perdi pai mãe irmãos." (Não sei dançar, 1925.)

Também rompe barreiras com a introdução de modos de dizer populares, de entoação gostosa, segundo o uso modernista:

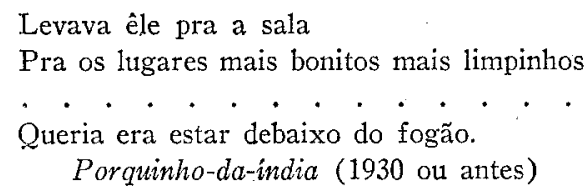

"A mim - escreveu - sempre me agradou, ao lado da poesia de vocabulário gongorinamente seleto, a que se encontra não raro na linguagem coloquial e até na do baixo calão." (Itinerário de Pasárgada, pág. 96). O poeta nem desdenhou brincar com o som das palavras. Quando são palavras ameríndias e africanas, vai além da mera incrustação de nomes exóticos:

Os aguapés dos aguaçais

Nos igapós dos Japurás

Berimban (1924 ou antes)

ou :

Capiberibe, Capibaribe

Evocą̧ão do Recife (1925)

ou ainda :

$$
\begin{aligned}
& \text { Meriti meretriz } \\
& \text { Mangue (1930 ou antes) } 17
\end{aligned}
$$

Mais tarde reintroduz a pontuação, mas a ampliação do vocabulário continua. Sem exagerar o emprêgo da língua falada, exprime graças a ela, a sua emoção com maior intensidade. Vem ao caso o uso que faz da palavra "desinfeliz" para indicar a tristeza incurável:

Estou desinfeliz

Ó maninha 0 maninha.

Dedicatória (1944 ou antes) 
O poeta se inspira nos progóes da rua desde Meninos carvoeiros (1921), como antigamente se inspirara nas vozes da terra, de animais noturnos- aves e sapos sobretudo:

a voz humilde e lamentosa dos pássaros da treva Paisagem noturna (1912)

Finalmente, acolhe todos os ruidos caóticos da cidade:

$$
\begin{aligned}
& \text { o sussurro sinfônico da vida civil. } \\
& \text { Comentário musical (1930 ou antes) }
\end{aligned}
$$

Mas é à música verdadeira que sempre se abre a alma do poeta de par em par - primeiro à impressionista e romântica, ${ }^{18} \operatorname{logo}$, depois da guerra de 1914, aos ritmos febris e os sons estridentes do jazz:

Sim, já perdi pai mãe irmãos.

Perdi a saúde também.

É por isso que sinto como ninguém o ritmo do jazz-band.

Não sei dançar (1925)

Melhor que Bilac, assimila então a música do povo, os choros, os sambas e as marchinhas carnavalescas do Rio: "Passa um clangor de clubs lá fora." (Rondó do Palace Hotel, 1936 ou antes). Inclui farrapos das letras dessas músicas:

$$
\begin{aligned}
& \text { Com choros de cavaquinho, pandeiro e reco-reco } \\
& \text { Es mulher } \\
& \text { És mulher e nada mais } \\
& \text { Mangue (1925) }
\end{aligned}
$$

No mesmo poema ouve-se o canto duma macumba; em outro o dum maracatu pernambucano. ${ }^{19}$

Entramos em cheio no folklore, cujo estudo renasceu no Brasil por aqueles anos de pós-guerra, devido a João Ribeiro e Afrânio Peixoto. O poeta, seduzido pelo som das palavras, esquece-se da licorne, dos faunos, das ondinas e das sereias que assomaram desde 1913 (em Mar bravo) pelo menos nas suas poesias feitas à moda simbolista. Diverte-se quando em Berimbau faz menção do saci, da iara, do bôto e do cussaruim da "Amazônia que eu nunca vi.". 20 Chega a uma síntese somente depois de integrar êsse folklore ser- 
tanejo na poesia urbana, um pouco à maneira de Mário de Andrade, o amigo cuja influência o avassalava então. Faz intervir wiaras e sereias no poema Mangue, assim como insere um pedaço das "cheganças para o Natal", especialidade de Mário.

Os jogos infantis, as cantigas de roda, os acalantos haviam de fornecer-lhe ritmos ingênuos desde $O s$ sapos de 1918. Passa a evocá-los de preferência, como afirma no Itinerário de Pasárgada (pág. 10):

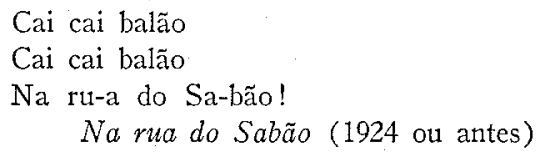

Finalmente consegue casar à perfeição determinado ritmo poético com quadras populares nas onomapoéticas poesias Os sinos, de antes de 1924, e Trem de ferro, de 1936 ou antes:

Oô

Vou mimbora vou mimbora

Não gosto daqui

Nasci no sertão

Sou de Ouricuri.

Oô...

Vou depressa

Vou correndo

Vou na tôda

Que só levo

Pouca gente

Pouca gente

Pouca gente...

\section{Gerald M. Moser, Pennsylvania State University.}

\section{$\mathrm{NOTAS}$}

1 Assim se explicará o porquê da atração exercida por Bandeira nos jovens. "Na minha vida de poeta os meus contatos tem sido sempre com gente nova, o que talvez explique que eu venha envelhecendo de vagar." (Itinerário de Pasárgada, pág. 129.) Também pode ser que perdeu a idade certa. por causa da má sorte prematura: 
Meus vinte anos vão tão distantes!

Pensando bem, jamais os fiz.

Enfermo, envelheci muito antes.

Aprendi a ser infeliz.

Madrigal para as debutantes de 1946

Segundo Moreyra perteneciam à sua geração e a de Bandeira Mário Pederneiras, Marcelo Gama, Eduardo Guimaraens, Raul de Leoni, Hermes Fontes, Felipe d'Oliveira, Ronald de Carvalho, Guilherme de Almida. Todos êles acabaram tràgicamente, com excepção do último, de Moreyra e de Bandeira. As opiniões indulgentes de Bandeira sobre os companheiros de geração encontram-se na Apresentação da Poesia brasileira de 1946.

2 "A guerra foi um cataclismo que abalou a sensibilidade dos rapazes mais fundo do que economia internacional. Um na mão, melhor que cem voando. A esposa real. De um dia, de uma hora, seja! mas real, bem real." (Crônicas da Província do Brasil, pág. 259.) Idêntica ideia revela-a o Madrigal melancólico (1920), na sua última linha: "O que eu adoro em ti, é a vida."

3 Com referência ao primeiro livro de Manuel Bandeira, seú antigo mestre João Ribeiro o saudou assim em 1917: "De tal arte nos haviam estragado o gôsto com o abuso das convenções, dos artifícios e das nigromâncias mais esdrúxulas, que esta volta à simplicidade e ao natural é uma reparação consoladora e saudável. Saindo daquele atordoamento de luzes multicolores, de lanternas nipônicas, reentramos com o poeta no frescor ameno das sombras." A citação vem em "Manuel Bandeira fala de sua obra", de Paulo Mendes Campo, Provincia de São Pedro, núm. 13 (1949), pág. 166.

4 Mar que ouvi cantar murmúrios

$\mathrm{Na}$ doce queixa das elegias,

Como se fôsses, nas tardes frias

De tons purpúreos,

A voz das minhas melancolias.

$$
\text { Mar bravo (1913) }
$$

Será da mesma época o poema Oceano:

Ulula o mar, que não vejo,

Naquela voz sem consôlo,

Naquela tristeza imensa

que há na voz do meu desejo.

5 "Verdes mares bravios de minha terra natal, onde canta a jandaia nas frondes da carnaúba; ... Onde vai a afouta jangada, que deixa rápida a costa cearense, aberta ao fresco terral a grande vela?" Assim começa Iracema, a lírica novela de José de Alencar. 
Manuel Bandeira reage aqui contra a literatice, o "envenamento de literatura” que, segundo acha Álvaro Moreyra, caracteriza a sua geração.

6 Versão traduzida da inglesa em William Hung, Tu Fu, China's Greatest Poet, Cambridge, Mass.; 1952. (Poema núm. 85.)

7 Itinerário de Pasárgada, pág. 127.

8 ..."o Brasil visto directamente, o Brasil cheirado em alguns versos de Ronald, sentido directamente nas introspecções de Manuel Bandeira e Mário de Andrade." Gilberto Amado, "Para dentro da cidade", Boletim de Ariel, junho de 1934.

9 Cidade do interior, cêrca de 1925, citado no artigo de Paulo Mendes Campo, a pág. 168. Ecoa à moda modernista o poema Berço, publicado em 1901 por Bernardino Lopes ("recordo: um largo verde e uma igrejinha"...)

10 Epigrama citado com aprovação pelo próprio Bandeira em Panorama de la poesía brasileira, México, 1951, pág. 94.

11 O juizo de Mário de Andrade, amigo pessoal de Bandeira, se encontra numa recensão das Poesias Completas dêste: "Nem é o que se chama um triste de verdade. Antes um solitário. Por adaptação ainda mais que por índole pessoal. Gosta da vida, eu sei. Muitíssimo." (Revista do Brasil, vol. xxvII, 1924, pág. 214).

12 Et ton rire trempé de pleurs qu'on ne voit pas

\section{La muse vénale (1857).}

O papel do palhaço na arte contemporânea desde o simbolismo foi definido pelo crítico Wallace Fowlie em The Clown's Grail, Londres, 1948.

13 "As influências literárias que fui recebendo são incontáveis." (Itinerário de Pasárgada, pág. 29).

14 Escrevendo um dia um artigo sobre seu xará, o artista pernambucano Manuel Bandeira, suspirou: "Eu não hesitaria um minuto em trocar por meia dúzia de desenhos do xará tôda a versalhada sentimentalona que fiz, em suma, porque não pude fazer outra coisa." (Crônicas da Província do Brasil, pág. 116.)

15 Ålvaro Moreyra, "A nossa geração", pág. 129. Outro aspecto do fragmentarismo de geração foi o cubismo dos pintores.

16 Desde 1909 Guillaume Apollinaire publicou no Mercure de France poesias sem pontuação em que transformava o cotidiano urbano em matéria imagista: "Des troupeaux d'autobus mugissants près de toi roulent," Também cultivava a brincadeira meia séria, por exemplo em Annie, a fantástica menonita do Texas, na coleção Alcools (1913). 
17 Pertencem à mesme tendência os jogos onomásticos de Bandeira sobre nomes tais quais Maria Augusta "Magu": "Magu, Magu, maga magra,

$$
\begin{aligned}
& \text { Magra Magu..." } \\
& \text { Mafuá do Malungo. }
\end{aligned}
$$

Parecidos resultados poéticos deu a mania etimológica de Unamuno.

18 Abundam nas suas primeiras poesias os ecos de Debussy, Schumann, Schubert. Mais tarde acrescentam-se Haydn e Mozart. Nota-se a ausência da música italiana, antigamente tão popular no Brasil.

19 O maracatu inspirou o poema Boca de forno, de 1936 ou antes. Gilberto Freyre contou em Perfil de Euclydes e outros Perfis (Rio de Janeiro, 1944) como o poeta conheceu o maracatu numa silenciosa noite pernambucana, durante a segunda visita ao Recife em 1928 ou 1929: "O poeta esperou-o parado, até que se encontraram, o barulho do Maractú já enorme. A emoção do poeta creio que foi também enorme naquele instante." (Pág. 179).

20 Veja-se ao respeito o Itinerário de Pasárgada, a pág. 72.

\section{OBRAS CONSULTADAS}

Bandeira, Manuel, Crônicas da Província do Brasil. Rio de Janeiro, Civilização Brasileira, 1937.

, Guia de Ouro Preto. Rio de Janeiro, Serviço do Patrimônio Histórico e Artístico Nacional, 1938.

-_, Itinerário de Pasárgada. Rio de Janeiro, Jornal de Letras, 1954.

- Mafuá do Malungo. Versos de circunstancia. Nova edição aumentada. Rio de Janeiro, Livrarià São José, 1955.

-, Panorama de la poesia brasileña. México, Fondo de Cultura Económica, 1951. (Tradução espanhola de Apresentação da poesia brasileira. Rio de Janeiro, Casa do Estudante do Brasil, 1946.)

-, Poesias. Sexta edição aumentada. Rio de Janeiro, José Olympio, 1955.

___. Poesias completas. Segunda edição. Rio de Janeiro, Civilização Brasileira, 1940. 1944.

Poesias completas. Terceira edição. Rio de Janeiro, Americ. Edit, Poesias escolhidas. Primeira edição. Rio de Janeiro, Civilização Brasileira, 1937. 